\title{
Breaking out of the policy enclave approach to child labour in sub-Saharan African agriculture
}

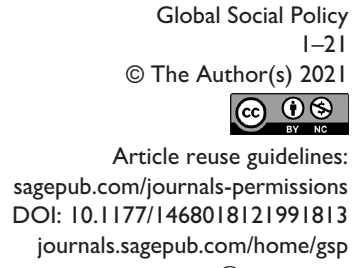

@SAGE

\author{
Rachel Sabates-Wheeler (iD \\ and James Sumberg \\ University of Sussex, UK
}

\begin{abstract}
This article is framed by the tension between a substantial universalising framework of global instruments on workers' rights and child labour on one hand, and their outsourced implementation through the social policy enclaves of transnational corporations on the other hand. It uses the concept of 'social policy enclaves' to explore this tension and how it might be resolved to the benefit of children who work in African agriculture. To do this, the article steps back from dominant discourses around child labour, and examines how a re-framing of children's involvement in African agriculture, from labour to work, might enhance understanding of the forms, prevalence, drivers and dynamics of their involvement in work that is harmful. A deeper understanding of these issues should help to inform a revitalised universal approach to social policy in respect to children's work.
\end{abstract}

\section{Keywords}

Agriculture, child labour, children's work, Ghana, harm, social policy

\section{Introduction}

Between the establishment of the International Labour Organization (ILO) in 1919, and the late 1980s, global social policy addressing labour was developed and consolidated through a series of international instruments. ${ }^{1}$ These, in turn, have had a widespread influence on national statutes and regulatory regimes. Arguably, this represents a global social policy success: the right to protection from all forms of hazardous and exploitative work

\section{Corresponding author:}

Rachel Sabates-Wheeler, Institute of Development Studies (IDS), University of Sussex, Brighton BNI 9RE, UK.

Email: R.Sabates-Wheeler@ids.ac.uk 
is now universally accepted, if inconsistently and imperfectly applied. Since the 1980 s, reflecting the rise in neo-liberal social policy coupled with labour market deregulation (Picciotto, 1999), labour relations have been increasingly influenced by voluntary codes developed or subscribed to by transnational, typically northern-based, corporations (Henson and Humphrey, 2010; Locke et al., 2013; Marx et al., 2012). Such codes, which generally build on the international instruments, are now a significant force in shaping labour conditions within global supply chains. Accompanying this has been the growth of the ethical investment movement reflecting investors' concerns with social and environmental performance (Sparkes and Cowton, 2004). The interest in setting and meeting social and ethical standards reflects pressure from a variety of stakeholders - including labour, customers and shareholders - concerned about labour practices in less developed countries. The expression of social and ethical values in the global marketplace is nowhere more apparent than in relation to child labour (Ferguson, 1999). A commitment not to use child labour is central to most voluntary codes and standards, due in large part to media attention to, and emotive power of, claims of child labour, abuse and exploitation.

However, Pearson and Seyfang (2001) argue that social policy as enacted by transnational corporations 'appears to be more enclave than universal, since their concerns and responsibilities are delineated not by the global potential of the universe in which they operate but the specific localisation of the particular production processes' (p. 66). For example, voluntary standards and codes of conduct play a part in the governance of value chains that deliver high-value and high-visibility products to consumers in the global north, including tea, coffee and cocoa from sub-Saharan Africa (SSA). In contrast, they play no part in lower profile value chains that move domestically produced maize, cassava, fish or vegetables to local markets, and in which transnational corporations have little if any involvement.

This article is framed by the tension between a substantial universalising framework of international instruments protecting workers' rights and regulating child labour on one hand, and a value-chain specific approach to implementation on the other hand. Specifically, we use the concept of 'social policy enclaves' to explore this tension and how it might be resolved to the benefit of children who work in African agriculture. We focus on agriculture because it is associated with the vast majority of child labour (and children's work more broadly) in SSA (ILO, 2017).

The argument we develop is that the voluntary codes around which policy enclaves in African agriculture are forged, as well as the body of global social policy that underpin them, reflect very particular views of children, childhood, and children's economic activity. These views are manifest in, for example, the formal definitions of child labour, hazardous work and so on, which, when operationalised in surveys, suggest that significant numbers of children are in child labour, while they are also living at home and in many cases attending school. However, these views, definitions and associated metrics, and the estimates of child labour and hazardous work that they generate, do not reflect either the economic realities or the cultural and social contexts within which most rural children and their families live. Finally, we argue that the objective of universalising coverage of all rural children can best be achieved, not by extending the enclaves, but rather through a better understanding of children's work in context, and specifically of the work through which they actually experience harm. This will require some nuancing of the universal frameworks. 
The article proceeds as follows. The next section explores the notion of social policy enclaves, their relevance to child labour in African agriculture, and the empirical and conceptual challenges in addressing child labour in agriculture. The significance of a discursive re-framing of the problem of child labour as children's work is highlighted. Following this, a simple lexicon is developed that includes terms and concepts that are central to our emerging understanding of children's work and children's harmful work. The penultimate section explored several aspects of the argument in more detail, and the final section concludes.

\section{Policy enclaves and the case of child labour in African agriculture}

\section{Policy enclaves}

The notion of a policy enclave is used in two ways in the literature. In the first, an active state defines and controls a geographically delimited area, endowing it with regulations and incentives that are different from those in force outside the enclave. The establishment of such an enclave creates a 'dual legal order' which separates it from the rest of the jurisdiction in which it is located $(\mathrm{Hu}, 2020)$. For example, special economic zones (SEZ) are policy enclaves offering an advantageous incentive regime to businesses which locate within them (The World Bank, 2008). Such enclaves are created to realise micro-economic, macro-economic and political objectives including employment generation and regional economic development. We might think of these as state-active enclaves.

In contrast, 'policy enclave' is also used to refer to areas, sectors or value chains from which the state has essentially stepped back from the setting and/or implementation of policy (i.e. state-passive enclaves). This is the sense in which Pearson and Seyfang (2001) discuss the enactment of social policy by transnational corporations. The suggestion is not that the corporations will necessarily be less ambitious or effective than the state, or seek to distance themselves from universal frameworks. Indeed, in most cases, the social policy aspects of the voluntary codes to which they subscribe, for example, through participation in certification schemes like the Better Cotton Initiative and Rainforest Alliance, reflect both the universal frameworks and relevant national legislation. Nevertheless, the creation of policy enclaves like these results in a value-chain lottery, giving protection to child workers in only specific value chains and locations. These state-passive enclaves thus challenge the universalist principle that is the basis of both global and national social policy.

In this article, we are interested in the emergence of state-passive policy enclaves in African agriculture, and specifically, whether they help or hinder efforts to address children's involvement in any and all agriculture work that harms them.

\section{Agriculture, child labour and social policy enclaves}

Cocoa is produced for export by small-scale family farmers in SSA on 8 million ha of land, of which $87 \%$ is located in just three countries (Cote d'Ivoire, Ghana and Nigeria). ${ }^{2}$ 
Much has been claimed and contested about the use of child labour in West African cocoa production, including reference to widespread exploitation, slavery and trafficking (e.g. Ould et al., 2004; Romano and Mistrati, 2010; School of Public Health and Tropical Medicine, 2015; Sustainable Tree Crops Programme, 2002). There have been and continue to be numerous high profile initiatives to address - indeed eliminate - child labour in West Africa's cocoa production, including the Harkin-Engel Protocol (Bertrand and De Buhr, 2015), ${ }^{3}$ and initiatives by governments (Amoo, 2008), international agencies (ILO-IPEC and Murray, 2007), firms (Nestle Cocoa Plan, ICI, 2017), certification bodies (Ingram et al., 2018) and non-governmental organisations (NGOs).

In contrast, maize, which is grown on 39.5 million ha across the length and breadth of $\mathrm{SSA}^{1}$ (including the cocoa producing areas of West Africa), is also produced predominately by small-scale farmers, for home consumption and domestic markets. However, there has been little discussion of child labour specifically in relation to maize production, little research that interrogates the existence or prevalence of child labour (see, for example, Carter, 2017), and consequently, few if any remediation initiatives.

The obvious question is why is child labour a cause célèbre in the cocoa sector, while it is seldom mentioned in relation to maize? Two possible explanations present themselves. The first is that there is something fundamentally different about the ways, or the contexts within which, cocoa and maize are produced, that result in real differences in the forms and prevalence of child labour. Perhaps, the tasks in cocoa production are particularly suited to children (the classic 'nimble fingers' argument, see Grootaert and Kanbur, 1995); or children's labour is required at particular times in the cocoa farming calendar to complete time-critical tasks; or cocoa farmers are so resource constrained that they have no choice but to put children to work. However, we know of no evidence that would support these explanations: indeed, if anything, at least in the case of Ghana, there is relatively less poverty in cocoa growing areas (Ghana Statistical Service, 2015); and more broadly, children seem to work to varying degrees, in the production of many if not all crops grown on Africa's family farms (Dachille et al., 2015).

The second possible explanation is that the forms and prevalence of children's involvement may actually be very similar, but, differences in the product (a luxury good vs a staple food); the market (international - northern vs domestic - regional); the role of international agri-business (significant vs non-significant); and the spatial concentration of production (high vs low) result in much greater attention being paid to their work in cocoa compared to maize. Here, the argument is that the particular configuration of the West African cocoa sector, the international chocolate industry, associated policy coalitions, and political and consumer interests in the north (including around human rights due diligence legislation), brings children's work on cocoa farms into the highly formalised discursive and regulatory worlds of child labour. This is not the case for the work done by children on maize farms, even if those farms are in cocoa producing areas and the work is broadly similar.

If this second explanation is correct, it does not necessarily follow that the policy enclaves should be expanded to support interventions to eradicate child labour from maize production (as in, for example, the 'child labour free zone' (CLFZ) approach - see Szyp, 2020). Rather, it more fundamentally calls into question the framing of so much of children's involvement in cocoa production as child labour, with all the negative 
connotations associated with the term. For example, using data collected in 2013/2014, a study by the Tulane University School of Public Health and Tropical Medicine (2015) estimated that an astounding $96 \%$ of children working in cocoa production were 'child labourers' and $91 \%$ were in hazardous work. What makes these figures particularly surprising is that only $23 \%$ of these 'child labourers' and the children doing hazardous work were not residing with a biological parent, while over $90 \%$ reported attending school in the previous 12 months.

Of course, this is not simply a story about cocoa and maize. State-passive policy enclaves have also emerged to address children's involvement with other smallholder export-oriented commodities including coffee, tea and cotton. As with the cocoa case, children's work associated with these crops is viewed through the lens of child labour and its 'unconditional worst forms'4 (which unhelpfully puts slavery in the same box as children using a machete on their parents' farm). However, as with maize, the work that children do on cassava, rice or other food crops receives little attention. ${ }^{5}$

\section{The empirical challenge}

There are many estimates of the prevalence of child labour in rural Africa arising from comparative, national and sector studies. For example, in Ghana a nationwide survey in 2001 estimated that that there were 3,963,040 children aged 5-17 in rural areas, of which $39.6 \%$ had worked in the 7-day period preceding the survey (Ghana Statistical Service, 2003). In total, $31 \%$ of rural respondents reported, 'having ever been injured or suffered illness at workplace or while working'. On the basis that Ghana's Children's Act prohibits even light work by children under 13 years, the authors estimated that 1,031,220 children nationwide could be said to be in 'child labour', which increased to 1,273,294 (80\% of whom were in rural areas) if those doing hazardous work were included. However, the report notes that 'Ghanaian culture' recognises the importance of children's involvement in light work in guiding them to become responsible adults. Furthermore, because 'such social and cultural considerations have not been reflected in the law, not all the estimated number could actually be said to be in child labour' (p. 137, emphasis added).

Another nationally representative survey in Ghana in 2014 estimated that $38.3 \%$ of children aged 5-17 in rural areas engaged in economic activity (GSS, 2014). In Upper West region, well north of the cocoa production zone, $45.2 \%$ of children were in economic activity, and this region also had the highest proportion of economically active children engaged in agricultural activities (92.4\%). Overall, 30.2\% of rural children were reported to be in child labour and $20 \%$ in 'hazardous forms of child labour'. In 'rural forest' areas, which would include most cocoa areas, $30.0 \%$ and $21.3 \%$ of children were in child labour and hazardous forms respectively, compared to $34.6 \%$ and $20.9 \%$ in 'rural savannah' (i.e. northern) areas. We have already made reference to the intensive survey work in 2013/2014 in Ghana's cocoa producing areas which concluded that the vast majority of children working in the cocoa sector were 'child labourers' and in 'hazardous work' despite living at home and going to school (School of Public Health and Tropical Medicine, 2015).

Surveys like these, and the resulting estimates of economically active children and those in child labour and/or hazardous work, face significant methodological challenges. 
Particularly at the lower end of the age range, 7-day or 12-month recall data on type, frequency and hours of work reported by children or their parents must be unreliable. This is particularly so because of the intricate, age-specific definitions of acceptable and unacceptable work. Given the public attention to and legal restrictions around children's work, it is also likely that parents, when questioned, will be less than open. But more fundamentally, these surveys suffer from the limitations associated with the complex terminology associated with the international instruments, including ILO Conventions 138, 182 (ILO, 1973, 1999), and made operational through derivative national legislation and regulatory regimes (Amoo, 2008; Government of Ghana, 1998; Okyere et al., 2020). Research designs and survey instruments must navigate a tortured path between legally acceptable, age-appropriate types and hours of work - including distinguishing between light work, regular work - hazardous work and 'worst forms' of child labour (Noguchi, 2002). As noted in the report of the 2001 survey (Ghana Statistical Service, 2003), and further developed by Okyere et al. (2020), the fact that most surveys take no account of local norms, household needs, seasonality, local availability of quality of schools and so on, only increases the gulf between the international instruments, national legislation and rigorous survey design on one hand, and the place of children's work in rural lives and livelihoods on the other hand. Ultimately, the objective of child labour surveys is usually to categorise children using a simple dichotomy of 'in child labour' or 'not in child labour' (or 'in hazardous work' or 'not in hazardous work'), which leaves little room for the complexity, ambiguity and contingency of real lives and livelihoods. Taken together, these represent serious impediments to both analysis and effective remedial action.

\section{The conceptual challenge}

Even more fundamental than the empirical challenge outlined earlier is an important conceptual challenge. The idea that child labour is a social ill, and must be eliminated, has given rise to a significant body of global social policy. Following Deacon (2004), this policy seeks to address child labour through actions relating to both global social regulation and global social rights. Underpinning it and its associated discourse is an imaginary in which children are innocent, vulnerable and in need of adult and, by extension, state protection, and childhood should be all about family, play, school and learning. A recent example of this can be seen in FAO's e-learning course 'Introduction to child labour in agriculture', ${ }^{6}$ slide 3 (entitled 'What is a child?') states, 'A child is defined as any person under 18. During their childhood, children should: play and have fun with peers; study; be cared for and protected from hazardous conditions' (emphasis added). In contrast, Peleg (2018) shows that when children make demands that exceed imaginary boundaries of protection, their voices are dismissed on the basis of immaturity. He argues that paternalistic understandings of childhood and the way that childhood can unfold has stymied the ability of international children's rights law to both protect and empower children.

Yet, over the last two decades there have been moves to situate child labour within a broader understanding of children's work (Bourdillon and Carothers, 2019; Bourdillon et al., 2010; Boyden and Ling, 1998). The motivation is not to deny or diminish the exploitation and harm that some children experience while working, but to understand children's work, and the benefits and harms that arise from it, as part of the larger canvas 
of children's economic and social worlds. Bourdillon and his colleagues have devoted substantial time establishing, both theoretically and empirically, the case that many children throughout the world value both education and work. Work has important social, economic and cultural benefits that sometimes outweigh the benefits of education and sometimes enable education (for instance, work can provide money for school enrolment, Aufseeser, 2014). In other words, the idea that there is always a benefit trade-off between work and school is misplaced. Bourdillon and Carothers (2019) argue that policy on children's work 'should be based on sound contemporary understandings of childhood which [. . . is continuous with human life' (p. 5). Policies should be as concerned with protecting children's opportunities for work as they are with protecting them from harmful work. Liebel (2013) argues for the development of a concept of decent and dignified work for children, and the important role that children's movements and organisations, such as the African Movement of Working Children and Youth (AMWCY) can and are playing (Liebel, 2012).

This relatively new focus on children's work is underpinned by an alternative conception of children, in which their vulnerability and need of protection are tempered by their individual and collective agency (Aitken, 2001; Robson, 2004). Thus, not only do many children in SSA work, and often willingly, but they are also social and economic actors in their own right, exercising varying degrees of agency in relation to the opportunities and constraints that shape their lives (Van Hear, 1982; Xolocotzin and Jay, 2020).

Tisdall (2017) questions the traditional and limited characterisation of children as 'vulnerable' - stating that 'in much of liberal theory on rights, children are either absent from the theorisations or set up as the counter-example' (p. 62). Instead, Tisdall argues that vulnerability is a universal human condition, and that the state has a positive obligation to ensure protection for all. This naturally leads one to question the emphasis on the role of adults in defining children's vulnerabilities and acting to protect them, rather than children and young people's participation in identifying their own concerns and ways to address them.

Fawcett (2009), too, is concerned with how 'vulnerability' can be used to constrain people's rights to make decisions, separating them out from their social networks which in turn makes them more 'vulnerable'. Thus, some theorisations of vulnerability can lead to control and disempowerment of one group over another. This critique is used to justify a greater emphasis of children's participation in decisions that affect them, and in facilitating children's efforts to hold power to account (Tisdall, 2017).

It is also the case that children often constitute part of family strategies to assure food and income security, with the expectation that they take on certain responsibilities, including work and even migration, to help insure the family against destitution (Ansell and Van Blerk, 2004; Orellana et al., 2001). Much of children's economic activity is experienced as positive and empowering, or at least necessary, by the children themselves, their families and communities (Aufseeser et al., 2018; Bourdillon et al., 2010).

Clearly, the benefits and impacts of children's work on the child and the family will depend on a myriad of factors including age, age-specific and non-age related capabilities and vulnerabilities related to physical, physiological and psycho-social development, as well as the nature of work and work environment. A 5-year-old child will be in a distinctly different position to a 17-year-old; an immature 12-year-old will be 
in a different position to relatively mature 12-year-old; and a disabled child will be in a different position to an able-bodied child. But the general argument is that children's work, and in our case, their agricultural work, is on balance beneficial - for the child, for her or his family, and for society. This way of thinking is beginning to be influential: the distinction between children's work and child labour is now acknowledged by the ILO, as are the beneficial aspects of some children's work. ${ }^{7}$

\section{Children's work: an alternative lexicon}

A key part of our argument is that the ambition to create an effective universal framework to protect children from work-related harm will be achieved only when the concepts, definitions and associated metrics - and the estimates of child labour and hazardous work that they generate - reflect both the economic realities and the cultural and social contexts within which rural children and their families live. In order to begin build a more nuanced picture of benefits and harms associated with children's work, it is useful to step back from the detail, complexity and prescriptive intent of the current international instruments and national regulatory regimes. The back-to-basics lexicon provided here is a step in this direction.

Children's work covers a wide range of activities, including household chores and paid and unpaid economic activity, but excluding schoolwork. Children's work may be: at home, on farms and in businesses, in markets, in mines, in school (e.g. working in a school garden or cleaning a school dormitory); individually or in groups; and full-time, part-time, seasonal, during the school year and/or during school holidays.

Children work for many different reasons. It may be expected of them, done willingly, or forced upon them (e.g. by an adult or by another individual, or by family circumstances). Most children work at some point, and in many cultures, a 'good' child is one who works (Pankhurst et al., 2016). Many children experience their work as positive and empowering (Aufseeser et al., 2018). Work can help children build their confidence and self-esteem, and also provide them with new experience and opportunities for learning, to access to money and to contribute to the household.

$A$ hazard refers to a danger that is inherent to a task or job, or an aspect or feature of a work environment. For example, the mere presence of pesticide and machinery of sharp tools on a farm are hazards. A workplace bully and a sexual predator also represent hazards. Excessive work hours may pose a hazard in relation to health, but also in relation to the opportunities foregone (such as education). Exposure to a hazard creates the potential for an individual to experience harm. However, it is important to remember that exposure to a variety of hazards is a fact of life; and there are hazards in every work environment. We expect different types and conditions of work to produce different hazardscapes.

Hazard management refers to efforts by society at large, the state, local institutions, employers, parents, and working children themselves ${ }^{8}$ to reduce children's exposure to workplace hazards, and/or help them navigate exposure to a hazard without being harmed. Effective hazard management can eliminate a hazard altogether; change the nature of a hazard; reduce exposure to a hazard; reduce the likelihood that a hazard will result in harm; reduce the severity, time frame of manifestation and/or reversibility of 
any resulting harm; or increase an individual's or household's ability to survive or thrive when harm is experienced resilience (Béné et al., 2014; Davies et al., 2013). Examples of hazard management include social norms, formal regulations (e.g. labour standards), training, provision of appropriately sized equipment, enforcement of worker's rights, monitoring schemes and work-based social protection.

In the example cited earlier, if the mere presence of pesticides on a farm is a hazard, their storage in a secure space, and the clear labelling of storage containers, are two ways that the hazard can be managed. Apart from some certification schemes, we would expect that on smallholder farms in rural Africa formal hazard management measures will be of little immediate relevance.

Hazardous work: the notion of hazardous work is rooted in an acknowledgement that every work task and work environment expose workers to one or more hazards. However, because the nature of these hazards varies significantly, as does the level and effectiveness of hazard management, jobs and work environments can be considered to sit along a continuum from minimally to extremely hazardous. Working around a piece of farm machinery without training or protective clothing might be very hazardous, but would be considerably less hazardous after the worker is trained and provided with appropriate protective equipment.

Harm is an identifiable negative impact on an individual or household arising from a specific workplace hazard. Harm might be physical, psycho-social (including stress and anxiety), harm to development (e.g. lost opportunities for schooling) and/or financial (i.e. lost income). Excessive hours of work, even that which is considered 'light' and age-appropriate, may interfere with educational access and outcomes to the extent that there is harm to a child's intellectual development, future livelihood and earnings (Ray and Lancaster, 2005). Important dimensions of work-related harm include its severity, reversibility and time to onset. The severity and reversibility of harm will reflect both the initial harm as well as any mitigating effect of, for example, prompt medical care. Again, exposure to a hazard does not always or necessarily result in harm: it is a necessary, but not a sufficient condition.

Children's harmful work refers to any work that children undertake that results in harm to the child and/or their household. The emphasis here is on the actual experience of harm resulting from work, as opposed to the potential to be harmed or the risk of being harmed. The shift from hazardous work to harmful work is mediated by the working conditions and the capabilities and vulnerabilities of the child worker. For example, a child who is not healthy but who is expected to work long hours is more likely to be harmed than one who is healthy and well-rested. More broadly, both the exposure to hazardous work as well as the experience of harm and its subsequent effects will intersect with a range of identity markers, such as ethnicity, age, gender and religion, that for example, may constrain the ability of an individual to exercise agency.

When harm does arise, its severity and reversibility will reflect both the nature of the harm and any mitigating conditions associated with the support system surrounding the child. This system might include a range of provisions including local knowledge about how to respond to particular harms, access to health services, availability of social protection and insurance systems, child protection services, and so on. In the absence of appropriate interventions to address the harm, even a simple wound may lead to long-term 
irreversible harm, for example, through secondary infection. Poverty exacerbates the experience of harm: we expect poor and more vulnerable individuals, in more isolated rural areas, to benefit less from mitigating conditions. The nature, severity and reversibility of the harm will determine the magnitude of the immediate and future impacts on the individual and her or his family.

This conception of children's harmful work is partially aligned with one aspect of 'the worst forms of child labour' as articulated in Article 3 of ILO Convention C182, which refers to 'work which, by its nature or the circumstances in which it is carried out, is likely to harm the health, safety or morals of children'. ${ }^{9}$ The critical distinction is: we focus on work that actually results in harm while C182 includes work that is likely to result in harm. We also depart from the convention in relation to child trafficking and child slavery. While these fall under the definition of 'the worst forms of child labour', we find it useful to separate, at least conceptually, harmful work from the range of possible explanations for how the child came to engage in the harmful work. For example, children might engage in extremely hazardous work, which eventually harms them, either voluntarily or involuntarily - because they want to, or in order to help their parents, or because they were trafficked or find themselves in slave-like conditions. The point is that while trafficking and slavery are clearly and always abhorrent, they are different from and should not be confounded with harmful work. At the same time, having been trafficked or working in slave-like conditions might well increase the likelihood of working in more hazardous situations or of being harmed.

\section{Discussion}

Our starting point is that the establishment of a body of global social policy, with the goal of protecting all children from work that harms them, is as important today as it was in the early-20th century. However, the current international instruments and frameworks, and the national policy that they underpin, have significant limitations. Specifically, the emergence of policy enclaves within African agriculture, based on these flawed instruments, creates a value-chain lottery that undermines the ambition to provide universal protection, even within individual countries. In the preceding sections, we have argued that a conceptual shift from child labour to children's work, and the more nuanced understandings of children's economic activities and social contexts that this shift allows, is required to re-energise the universal ambition.

In this section, we develop the argument in greater detail. We first suggest that children's harmful work must be understood and addressed as part of the larger story of exploitative labour relations. We then return to social policy enclaves and whether they will help or hinder universal approaches to children's harmful work in agriculture. The next section addresses the importance of acknowledging the existence of multiple perspectives on harm, and particularly in relation to invisible or hidden harms, and this is followed by the not uncommon case when the alternative to work is low-quality and potentially harmful schooling. We then return to the notion of vulnerability, and argue that a close focus on children's vulnerabilities risks hiding the fact that these are intimately tied to the vulnerabilities of their carers and communities. Finally, we identify some important implications for policy actors. 


\section{Children's harmful work and exploitative labour relations}

All attempts to address children's harmful work must be rooted in the understanding that throughout the world, people of all ages, not only children, are exposed to hazards, and are harmed through work. Furthermore, hazardous and harmful work are as much a part of informal, small-scale, family businesses - including farming - as work in factories, sweatshops, artisanal mines, or plantations. Small-scale farmers are harmed through their engagement with commodities or value chains that necessitate hazardous practices. The ever-present nature of hazards in the workplace, therefore, necessitates a response that is appropriate to the management of hazard and that can, at least in principle, be universally applicable.

We hypothesise that children's harmful work will generally be co-incident with (i.e. in the same sectors, commodities, value chains, locations, seasons and firms) harmful work generally. If this is the case, one is less likely to find children engaged in harmful work when labour conditions for other workers are unproblematic. Nevertheless, children may be of special interest simply because (1) they have some specific vulnerabilities that adults do not have; (2) they may be over-represented (as a share of all workers) in a specific sector or industry, due, for example, to weak or missing labour legislation and regulation (and associated lack of voice and representation); or (3) children are seen as having a comparative advantage over adults in performing the same tasks. In certain jobs, work environments or work regimes there may also be child-specific hazard-vulnerability combinations that increase the likelihood of harm. Work-induced fatigue that results in reduced school attendance or an inability to concentrate is one obvious example.

It follows from this that a political economy perspective will be important in allowing children's harmful work to be appreciated and analysed as part of a broader set of rural labour relations. Here, it will be critical to understand the impact of different value chain governance mechanisms (Ton et al., 2020) - including voluntary standards and certification schemes - as well as other ongoing changes to labour relations in and around African agriculture (e.g. Phiri, 2016; Webb, 2017).

\section{Value chains and scrutiny of children's work}

Earlier, we noted the prominence of West African cocoa compared to staple food crops in public and policy discourse around child labour, and the existence of social policy enclaves associated with the cocoa value chain. We questioned whether the emergence of such enclaves would help or hinder universal approaches to children's harmful work in agriculture.

There is a relatively high level of concentration and coordination within the cocoato-chocolate value chain (Oomes et al., 2016; Ton et al., 2008). This reflects the concentration of power in a relatively small number of very large international commodity and manufacturing firms; the legal and regulatory frameworks in which they function; and the importance of brands in the marketing of chocolate. In this sense, cocoa shares some important characteristics with the 'global value chains' described and analysed by Gereffi et al. (2005). The contrast with the major West African food crops could not be starker, in that international capital, formal firms, export markets, and branding play 
little if any role. The question is whether the nature of the value chains, and, in particular, the location of the market and level of coordination, drives fundamental differences in forms and prevalence of harmful children's work. Or alternatively, do the particular characteristics of the cocoa value chain rather act to narrowly focus the gaze of the media, civil society, policy makers and consumers in ways that exaggerate any problems there may be in cocoa?

The critical role of cocoa in the economies of Ghana and Cote d'Ivoire means there is a heightened political dimension to the cocoa sector: it is the African 'political crop' par excellence. But significantly, these politics play out far beyond the national sphere and they swirl around the extraordinary contradiction of chocolate being a symbol of luxury and indulgence for the western consumer, while, at least according to some observers, the beans themselves carry the deep stain of child labour. The strong media focus on this contradiction, combined with the inappropriate concepts and definitions promoted through the international instruments, frame both policy and public discourse in a way that is detrimental to a more universal approach to harmful children's work in African agriculture.

\section{Multiple perspectives on harm}

It should be clear that harm is a multi-dimensional concept - all potential or actual harm is not equally bad (or harmful), or necessarily even deserving of policy attention. The situation becomes more problematic when the trade-offs between the various benefits and harms associated with children's work are brought into the equation. At the extreme end, a child may be so poor that she or he will not survive unless she or he engages in hazardous work that is likely to cause harm (in the eyes of an outside observer). However, she or he is, without question, better off having engaged in the work. This example illustrates the need to understand and address harmful work in a nuanced and context-appropriate way - an absolutist approach that all harmful work, or even all hazardous work, must be eliminated might contribute to even greater harm to children.

For most children and families, the trade-offs are probably not so stark. Rather than the negative being actual harm, it is more likely to be a greater likelihood of harm. These trade-offs can only really be understood when the perspectives of children and their households are brought in, and particularly in relation to how hazards and harm are actually experienced (understood, managed, navigated, lived with). But, taking the perspectives of children and their families seriously will likely highlight the fact that in some (many?) situations, their views on hazards and harm do not align well with those of experts, regulators, or advocacy groups. While the very hazardous or exploitative aspects of children's work may be relatively unambiguous, this will not be the case in other situations. Here, we must anticipate that children's perspectives on what should be acceptable may be quite different from those of their parents, to say nothing of experts.

Different perspectives on hazards and harm reflect different views on what is acceptable or unacceptable, necessary or unnecessary. These arise because of different interests: a child may work because she or he wants to pay school fees or establish a level of independence; a household may push her or him to work in order to help address its acute food insecurity; a government or industry may want her or him to stop working, or to do only some particular kinds of work, in order to comply with national or regional human 
rights due diligence legislation, or protect their position in a competitive global market; and a UN agency may want to strictly define what work is acceptable or permissible for the child in order to fulfil its mandate to establish international, cross-sectoral norms. They also arise through differential access to information (e.g. of hard to observe, longterm negative effects of pesticide exposure), differential access to (or appreciation of) years of accumulated local knowledge and experience, and differential cultural frames.

Thus, the key question becomes harm according to whom? Whose analysis of the balance between benefits and harms counts (or should count)? Who gets to define what is acceptable? Should the analysis be framed around net harm - accounting for the tradeoffs in outcomes for both the child and the family - or is it overly academic, if not oxymoronic, to talk of the benefits of harmful work? Is it right to always privilege perspectives of children (or experts) over others? If not, how can this tension be resolved?

These questions become particularly important in relation to invisible or hidden harms. For example, it is conceivable that children may not consider inhalation of certain fumes, or exposure to pesticides, to be harmful, while medical evidence suggests they pose a real threat to future health. The temporal (lag) aspect of harm strengthens the case for a longitudinal perspective to understand (1) the cumulative impacts of invisible harm and (2) how the harm/benefit balance shifts due to changing conditions over time. It may also be helpful in resolving the potential tension between the perspectives of children and experts on hazards and harm. Children may be more likely to frame something as harmful when it has an immediate negative impact (e.g. carrying heavy loads) compared to when the impact manifests itself over a longer period of time (e.g. developing respiratory problems following exposure to fumes). In other words, there may be a need to give greater weight to children's perspectives on harm in considering immediate effects, and possibly more weight to what we know through other research about long-term effects.

\section{Hazardous work, harmful work and wellbeing}

We have already made the case that many people across the globe engage in work during childhood, and that it can be a positive and formative experience. This does not mean that work can or should be a substitute for participation in quality education, play-based socialisation or other critical experiences and opportunities that children need to lead healthy, satisfying and productive lives. But there is now general acceptance - at least rhetorically - that work by children around the home, in support of a family enterprise, or for others, is acceptable as long as it does not unduly impinge on or crowd-out educational opportunities.

Of course, underlying this view is an assumption that adequate, quality education is available. If not - as is the case in many poorer agricultural communities - then the question arises as to the net effect on the child's or household's wellbeing of prioritising school attendance over participation in farm work. Why send a child to school if the quality of education provision is so bad that they learn nothing, or the child's contribution to the household economy is essential for survival, or farm work offers more valuable learning opportunities? Moreover, what of the hazardous school environments that children, especially girls, must navigate (Bhana and Mayeza, 2019; Schwandt and 
Underwood, 2016). Is a hazardous school environment always preferable to hazardous work on the family farm? As discussed earlier, this will depend on vulnerabilities related to specific identity markers, hazards related to getting to and being at school, and the quality of safeguarding at school. In cases where the school system is weak and severely under-resourced there appears to be no ethical high ground for insisting on sending children to school.

This argument is even stronger in the case where the likelihood of harm from a workrelated hazard is low, and the training provided 'on the job' is more valuable in terms of future income and work opportunities than a very low-quality education. If there is an insistence on children being in school - as there is under the various international human rights instruments, and the vast majority of national education policies - then a potentially valuable way to think about the trade-offs (or synergies) between work and education is to use the lens of a minimum acceptable provision of opportunities and wellbeing for children. This shifts the onus of responsibility from the immediate environment of the child - that is, the parent, the household and the value chain - to the state, and its responsibility for the provision of basic services.

\section{Vulnerable children, vulnerable families}

The literature identifies three distinct types of vulnerability, which are useful when considering how to address vulnerability in the face of hazardous work (Jones and Holmes, 2010; Sabates-Wheeler and Roelen, 2011). Physical/biological vulnerability refers to the fact that children, in particular pre-teens, have different physical and biological needs from adults, and are harder-hit, both in the short- and long-term, when these needs are not met. There is sound evidence that malnutrition, lack of health care, and low levels of education, during infancy and childhood, have far-reaching and long-lasting detrimental consequences (Haverman and Wolfe, 1995). In other words, children who start life in a disadvantaged position are more likely to remain disadvantaged, so that exposure to hazard and the likelihood of harm will be higher for them. It is clear that physical and biological vulnerabilities will vary with both age as well as the poverty status of the household or context in which the child resides.

Dependency-related vulnerability refers to the fact that children (especially pre-teens) are by necessity dependent on adults or older siblings for their wellbeing and provision of basic needs. As children grow older, they become more economically and socially independent and are able to exercise agency; but on the whole, young children have limited freedom to make decisions about their own wellbeing. As such, children's relationships with adults are obviously open to abuse, and this can reinforce their vulnerability. As is well documented in the literature on girls working as domestics or pushed into sex work, their dependence on adults other than their parents for the provision of basic needs makes them particularly vulnerable to verbal, physical and sexual abuse (Bourdillon, 2009; Jacquemin, 2006). Young boys are more likely to be exposed to hazards through working in agriculture.

Finally, vulnerability arising from institutionalised disadvantage, or what some sociologists refer to as 'cultural devaluation disadvantage' (Kabeer, 2005) which is rooted in 
the devaluation of certain groups in society based on who they are perceived to be. Identity markers that are characteristic of cultural devaluation include poverty, gender, ethnicity and religion, as they are thought to denote persons of lesser worth following the dominant beliefs, perceptions and attitudes (Kabeer, 2005). If a society places little value on children, the vulnerabilities associated with this type of disadvantage present themselves as children's lack of voice, lack of recognition, lack of representation and often entrenched inequalities that can provide fertile grounds for deliberate abuse and exclusion. But even in less extreme cases, children, on account of their age, may be practically and legally constrained to claim their rights and hold duty-bearers to account (SabatesWheeler et al., 2009). Unlike the other vulnerabilities where the children's limited degree of autonomy is inherent to the fact of being a child for biological and physical reasons, this third vulnerability can be considered a social and cultural artefact that is put in place and reinforced by institutional structures.

It is clear that in general, children, depending on their age, are more vulnerable to hazard and more likely to be harmed than their adult counterparts doing the same task. Yet, taken on its own, this statement detracts from the broader context - in particular, the social context - in which children are situated within and dependent upon social networks. In other words, children are most often part of a family and its enterprises, while both contributing to and making claims on family resources. It is within a network of social and familial relations that children engage with work activities, which, even if legally forbidden, are frequently seen as appropriate to the culture and context in which they live.

In contexts of widespread poverty where vulnerability to food insecurity is high due to weather, climate or conflict related shocks, the likelihood of exposure to hazardous work and harm from work is compounded. In other words, children's vulnerability in relation to work must be seen, analysed and addressed within broader contextual or 'structural' vulnerabilities. As encouraged by Jones and Holmes (2010), child-sensitive interventions need to be informed by '[ . . .] an understanding of the multiple and often intersecting vulnerabilities and risks that children and their caregivers face' (p. 1).

While children have and exercise agency, particularly as they get older, their engagement in work, including work that is hazardous and harmful, must be understood through the lens of social relations and networks, and particularly family and intergenerational relations. Obligations, expectations, gender norms and tradition are important aspects of these social relations. We would expect that all the different kinds of factors that make families more vulnerable - single parent, limited assets, migrant, disability - will increase the likelihood of children within those families engaging in hazardous work and being harmed through work.

In summary, children's vulnerabilities are intimately tied to those of their carers and communities. Their practical needs are those which stem from their physical and biological vulnerabilities, while their strategic needs relate to their limited autonomy and relative invisibility within the population at large. This socio-political understanding of vulnerability implies that any intervention to affect change 'must be interrogated for the extent to which it enables those whose lives are affected to articulate their priorities and 
claim genuine accountability' from different implementing and 'provisioning' stakeholders (Nyamu-Musembi and Cornwall, 2004).

\section{Conclusion}

The designation 'child labour' evokes imaginings of harm, abusive and bonded relationships, slavery and trafficking. It is highly emotive, with a strong association with the illegal and exploitative employment of children, particularly outside the home. In this article, we contrast the emergence of policy enclaves to address child labour in some export-oriented agricultural value chains in SSA, with the lack of attention given to child labour in domestic agricultural value chains. This bifurcation clearly undermines the ambition of global policy in this area to address child labour on a universal basis.

But, the challenge is more fundamental than this. By unpacking what is meant by hazardous work, harm and harmful work, we have suggested that child labour, as it has been constructed in the international instruments, national statutes and public discourse, is not meaningful in the vast majority of situations and contexts in which rural African children work. This work typically takes place within family agricultural enterprises and in situations where poor families negotiate and navigate their livelihoods in contexts of uncertainty and limited access to quality social services, including education and health. Children combine work and school in most, if not all, corners of rural SSA. Their work is important to them, and their families. Of course, work can also sometimes result in harm, and in some cases, this harm is serious or can have long-lasting or debilitating effects. To the extent that harm arises from hazards associated with the work that children engage in, then action needs to be taken to reduce the potential for harm by managing and reducing these hazards.

Recognising that in the majority of cases, the work children do is not harmful to them - in fact, it likely benefits them - is a critical and necessary step to a much needed opening-up of policy dialogue in the otherwise closed 'child labour' space. The objective of this opening-up is to inform the design and implementation of a new generation of child-sensitive, and more successful, initiatives to address those situations in which children are actually harmed while working. The problem is that the complexity and rigidity of the current frameworks, definitions and metrics limit their value in framing, targeting and monitoring such actions, both inside policy enclaves and elsewhere. This is a case where global social policy must be much better at accommodating the varied economic, social and cultural contexts within which Africa's rural people, including children, live and work. Such an accommodation relies on the political will of organisations such as the ILO, as well as large transnational corporations and NGOs, to be courageous enough to consult with, listen to, and act upon the revealed preferences of millions of rural dwellers in African agriculture. This would go a long way towards revitalising a universal, but pragmatic approach to a critically important area of social policy.

\section{Funding}

The author(s) disclosed receipt of the following financial support for the research, authorship and/ or publication of this article: This report has been funded with UK aid from the UK government 
(FCDO). The opinions expressed are those of the authors and do not necessarily reflect the views or policies of IDS or the UK government.

\section{ORCID iD}

Rachel Sabates-Wheeler (iD https://orcid.org/0000-0002-3173-212X

\section{Notes}

1. Including for example ILO conventions: 87 and 98, protecting freedom of association and the effective recognition of the right to collective bargaining; 29 and 105, eliminating all forms of forced and compulsory labour; 138 abolishing child labour; 100 and 111, eliminating discrimination in respect of employment and occupation.

2. FAOStat, data for 2017.

3. The Harkin-Engle protocol is an international, voluntary, public-private agreement aimed at ending the worst forms of child labour and forced labour in the production of cocoa. The industry's pledge to reduce child labour in Ghana and Cote d'Ivoire by $70 \%$, had not been met as of late-2015, and the deadline was extended to 2020.

4. Article 3 of ILO Convention C182 on the Worst Forms of Child Labour Convention defines the term the worst forms of child labour as comprising the following: (a) all forms of slavery or practices similar to slavery, such as the sale and trafficking of children, debt bondage and serfdom and forced or compulsory labour, including forced or compulsory recruitment of children for use in armed conflict; (b) the use, procuring or offering of a child for prostitution, for the production of pornography or for pornographic performances; (c) the use, procuring or offering of a child for illicit activities, in particular for the production and trafficking of drugs as defined in the relevant international treaties; and (d) work which, by its nature or the circumstances in which it is carried out, is likely to harm the health, safety or morals of children.

5. See Van Hear (1982) for a fascinating glance into children's involvement in commercial rice production in northern Ghana during the 1960s and 1970s.

6. https://elearning.fao.org/course/view.php?id=507

7. The International Labour Organization (ILO) recognises that 'Not all work done by children should be classified as child labour that is to be targeted for elimination' and that 'Children's or adolescents' participation in work that does not affect their health and personal development or interfere with their schooling, is generally regarded as being something positive' (https://www.ilo.org/ipec/facts/lang-en/index.htm; also see ILO, 2018).

8. For example, Van Hear (1982) describes resistance and different forms of collective action by young people and children - including 'go-slows, sabotage, stealing rice, arson, blocking irrigation Channels' (p. 511) - as they sought to protect themselves against exploitation and harm while working on commercial rice farms in northern Ghana.

9. https://www.ilo.org/dyn/normlex/en/f?p=NORMLEXPUB:12100:0::NO::P121 00_ILO_CODE:C182\#A3

\section{References}

Aitken SC (2001) Global crises of childhood: Rights, justice and the unchildlike child. Area 33: $119-127$.

Amoo P (2008) Hazardous Child Labour Activity Framework for the Cocoa Sector in Ghana. Accra: Child Labour Unit, Labour Department, Ministry of Employment and Social Welfare.

Ansell N and Van Blerk L (2004) Children's migration as a household/family strategy: Coping with AIDS in Lesotho and Malawi. Journal of Southern African Studies 30: 673-690. 
Aufseeser D (2014) Limiting spaces of informal learning among street children in Perú. In: Mills $\mathrm{S}$ and Kraftl P (eds) Informal Education, Childhood and Youth: Geographies, Histories, Practices. London: Palgrave Macmillan, pp. 112-123.

Aufseeser D, Bourdillon M, Carothers R, et al. (2018) Children's work and children's well-being: Implications for policy. Development Policy Review 36: 241-261.

Béné C, Newsham A, Davies M, et al. (2014) Review article: Resilience, poverty and development. Journal of International Development 26: 598-623.

Bertrand W and De Buhr E (2015) Trade, development and child labor: Regulation and law in the case of child labor in the cocoa industry. Law and Development Review 8: 503-521.

Bhana D and Mayeza E (2019) Primary schoolgirls addressing bullying and negotiating femininity. Girlhood Studies - An Interdisciplinary Journal 12: 98-114.

Bourdillon M (2009) Children as domestic employees: Problems and promises. Journal of Children and Poverty 15: 1-18.

Bourdillon M and Carothers R (2019) Policy on children's work and labour. Children \& Society 33: 387-395.

Bourdillon M, Levinson D, Myers W, et al. (2010) Rights and Wrongs of Children's Work. New Brunswick, NJ; London: Rutgers University Press.

Boyden J and Ling B (1998) What Works for Working Children? Florence: Innocenti Publications International Child Development Centre and Rädda Barnen.

Carter B (2017) Prevalence and impacts of child labour in agriculture. K4D Helpdesk Report, Institute of Development Studies, Brighton, May.

Dachille G, Guarcello L and Lyon S (2015) Child and youth agricultural work in Sub-Saharan Africa: Perspectives from the World Bank Integrated Surveys on Agriculture Initiative. Working Paper, Understanding Children's Work Programme, ILO and Centre for Economic and International Studies (CEIS), Rome, September.

Davies M, Bene C, Arnall A, et al. (2013) Promoting resilient livelihoods through adaptive social protection: Lessons from 124 programmes in South Asia. Development Policy Review 31: $27-58$.

Deacon B (2004) The politics of global social policy. Presented at the UNRISD conference on Social Knowledge and International Policy Making: Exploring the Linkages, Geneva, Switzerland, 20-21 April.

Fawcett B (2009) Vulnerability: Questioning the certainties in social work and health. International Social Work 52: 473-484.

Ferguson C (1999) Global Society Policy Principles: Human Rights \& Social Justice. London: Social Development Department, Department for International Development.

Gereffi G, Humphrey J and Sturgeon T (2005) The governance of global value chains. Review of International Political Economy 12: 78-104.

Ghana Statistical Service (2003) Ghana Child Labour Survey. Geneva; Accra: ILO; Ghana Statistical Service.

Ghana Statistical Service (2015) Ghana Poverty Mapping Report. Accra: Ghana Statistical Service. Government of Ghana (1998) The Children's Act. Accra: Government of Ghana.

Grootaert C and Kanbur R (1995) Child labour: An economic perspective. International Labour Review 134: 187-203.

GSS (2014) Ghana GLSS6 child labour report. Available at: https://www.ilo.org/ipec/ Informationresources/WCMS_IPEC_PUB_25515/lang--en/index.htm

Haverman R and Wolfe B (1995) The determinants of children's attainments: A review of methods and findings. Journal of Economic Literature 33: 1829-1878. 
Henson S and Humphrey J (2010) Understanding the complexities of private standards in global agri-food chains as they impact developing countries. The Journal of Development Studies 46: $1628-1646$.

Hu J (2020) From SEZ to FTZ: An evolutionary change toward FDI in China. In: Chaisse J, Choukroune L and Jusoh S (eds) Handbook of International Investment Law and Policy. Singapore: Springer, p. 1.

ILO (1973) Convention C138 - Minimum age convention, 1973 (No. 138). Available at: https://www.ilo.org/dyn/normlex/en/f?p=NORMLEXPUB:12100:0::NO:12100:P12100 INSTRUMENT_ID:312283:NO

ILO (1999) Convention C182 - Worst forms of child labour convention, 1999 (No. 182). Available at: https:/www.ilo.org/dyn/normlex/en/f?p=NORMLEXPUB:12100:0::NO::P12100_ILO_ CODE:C182

ILO (2017) Global Estimates of Child Labour: Results and Trends, 2012-2016. Geneva: ILO.

ILO (2018) 20th International Conference of Labour Statisticians Geneva, 10-19 October 2018. Resolution to amend the 18th ICLS Resolution concerning statistics of child labour, ILO, Geneva. Available at: https:/www.ilo.org/wcmsp5/groups/public/—dgreports/—stat/documents/meetingdocument/wcms_667558.pdf

ILO-IPEC and Murray U (2007) Rooting Out Child Labour from Cocoa Farms: Paper No. 3 Sharing Experiences. Geneva: ILO-IPEC.

Ingram V, van Rijn F, Waarts Y, et al. (2018). Towards sustainable cocoa in Côte d'Ivoire: The impacts and contribution of UTZ certification combined with services provided by companies (No. 2018-041). Wageningen Economic Research.

Jacquemin M (2006) Can the language of rights get hold of the complex realities of child domestic work? The case of young domestic workers in Abidjan, Ivory Coast. Childhood: A Global Journal of Child Research 13: 389-406.

Jones N and Holmes R (2010) The politics of gender and social protection. ODI Briefing Paper 62, October. London: ODI.

Kabeer N (2005) Social exclusion: Concepts, findings and implications for the MDGs. Paper commissioned as background for the Social Exclusion Policy Paper. Department for International Development (DFID), London. Available at: http://www.gsdrc.org/docs/open/se2.pdf

Liebel M (2012) Children's work, education and agency: The African Movement of Working Children and Youth (AMWCY). In: Spittler G and Bourdillon MFC (eds) African Children at Work: Working and Learning in Growing Up for Life. Münster: LIT Verlag, pp. 87-112.

Liebel M (2013) Do children have a right to work? Working children's movements in the struggle for social justice. In: Hanson K and Nieuwenhuys O (eds) Reconceptualizing Children's Rights in International Development: Living Rights, Social Justice, Translations. Cambridge: Cambridge University Press, pp. 225-249.

Locke RM, Rissing BA and Pal T (2013) Complements or substitutes? Private codes, state regulation and the enforcement of labour standards in global supply chains. British Journal of Industrial Relations 51: 519-552.

Marx A, Maertens M and Swinnen JF (2012) Private Standards and Global Governance: Economic, Legal and Political Perspectives. Cheltenham: Edward Elgar Publishing.

Nestle Cocoa Plan, ICI (2017) Tackling Child Labour: 2017 Report. Vevey: Nestle and ICI.

Noguchi Y (2002) ILO Convention No. 182 on the worst forms of child labour and the Convention on the Rights of the Child. The International Journal of Children's Rights 10: 355-369.

Nyamu-Musembi C and Cornwall A (2004) What is the 'rights-based approach' all about? Perspectives from international development agencies. IDS Working Paper 234, November. Brighton: Institute of Development Studies. 
Okyere S, Frimpong Boamah E, Asante F, et al. (2020) Policies and politics around children's work in Ghana. ACHA Working Paper 7, Action on Children's Harmful Work in African Agriculture, January. Brighton: IDS.

Oomes N, Tieben B, Laven A, et al. (2016) Market concentration and price formation in the global cocoa value chain. SEO-rapport no. 2016-79, 15 November. Amsterdam SEO Amsterdam Economics.

Orellana MF, Thorne B, Chee A, et al. (2001) Transnational childhoods: The participation of children in processes of family migration. Social Problems 48: 572-591.

Ould D, Jordan C, Reynolds R, et al. (2004) The Cocoa Industry in West Africa: A History of Exploitation. London: Anti-Slavery International.

Pankhurst A, Crivello G and Tiumelissan A (2016) Children's work in family and community contexts: Examples from young lives Ethiopia. Working Paper 147, 8 March. Oxford: Young Lives.

Pearson R and Seyfang G (2001) New hope or false dawn? Voluntary codes of conduct, labour regulation and social policy in a globalizing world. Global Social Policy 1: 48-78.

Peleg N (2018) Illusion of inclusion: Challenging universalistic conceptions in international children's rights law. Australian Journal of Human Rights 24: 326-344.

Phiri DT (2016) Rural children's role in buffering household poverty through ganyu (piecework) in Zambia. Children's Geographies 14: 685-700.

Picciotto S (1999) Introduction: What rules for the world economy? In: Picciotto S and Mayne $\mathrm{R}$ (eds) Regulating International Business: Beyond Liberalization. London: Palgrave Macmillan, pp. 1-28.

Ray R and Lancaster G (2005) The impact of children's work on schooling: Multi-country evidence. International Labour Review 144: 189-210.

Robson E (2004) Hidden child workers: Young carers in Zimbabwe. Antipode 36: 227-226.

Romano UR and Mistrati M (2010) The Dark Side of Chocolate. Copenhagen: Alexander Street Press.

Sabates-Wheeler R and Roelen K (2011) Transformative social protection programming for children and their carers: A gender perspective. Gender \& Development 19: 179-194.

Sabates-Wheeler R, Devereux S and Hodges A (2009) Taking the long view: What does a child focus add to social protection. IDS Bulletin 40: 109-119.

School of Public Health and Tropical Medicine (2015) Final Report: 2013/14 Survey Research on Child Labor in West African Cocoa Growing Areas. New Orleans, LA: School of Public Health and Tropical Medicine, Tulane University.

Schwandt HM and Underwood C (2016) Engaging school personnel in making schools safe for girls in Botswana, Malawi, and Mozambique. International Journal of Educational Development 46: 53-58.

Sparkes R and Cowton CJ (2004) The maturing of socially responsible investment: A review of the developing link with corporate social responsibility. Journal of Business Ethics 52: 45-57.

Sustainable Tree Crops Programme (2002) Child Labour in the Cocoa Sector of West Africa: A Synthesis of Findings in Cameroon, Côte d'Ivoire, Ghana, and Nigeria. Ibadan: IITA.

Szyp C (2020) Living wage, living income, and child labour-free zones: Arguments and implications for children's work. ACHA Rapid Review No. 1, Action on Children's Harmful Work in African Agriculture, 23 April. Brighton: IDS.

The World Bank (2008) Special Economic Zones: Performance, Lessons Learned, and Implications for Zone Development. Washington, DC: The World Bank.

Tisdall EKM (2017) Conceptualising children and young people's participation: Examining vulnerability, social accountability and co-production. The International Journal of Human Rights 21: 59-75. 
Ton G, Hagelaars G, Laven A, et al. (2008) Chain governance, sector policies and economic sustainability in cocoa: A comparative analysis of Ghana, Côte d'Ivoire, and Ecuador. Markets, Chains and Sustainable Development Strategy \& Policy paper 12, 17 January. Available at: https://ssrn.com/abstract=1609686

Ton G, Thorpe J, Egyir I, et al. (2020) Value chain governance: Entrance points for interventions to address children's harmful work in agriculture. ACHA Working Paper No. 6, Action on Children's Harmful Work in African Agriculture, 6 November. Brighton: IDS.

Van Hear N (1982) Child labour and the development of capitalist agriculture in Ghana. Development and Change 13: 499-514.

Webb C (2017) Between precarity and paternalism: Farm workers and trade unions in South Africa's Western Cape Province. Global Labour Journal 8: 49-64.

Xolocotzin U and Jay T (2020) Children's perspectives on their economic activity - Diversity, motivations and parental awareness. Children \& Society 34: 424-442.

\section{Author biographies}

Rachel Sabates-Wheeler is a Professorial Fellow at the Institute of Development Studies (IDS) and a co-Director of the Centre for Social Protection. She has worked on areas of poverty analysis related to social protection, rural livelihoods and migration and displacement in many countries (including 9 African countries) and has published widely on these themes.

James Sumberg is an Emeritus Fellow at the Institute of Development Studies (IDS), Brighton, UK. An agriculturalist by training, his research has focused primarily on smallholder agriculture in sub-Saharan Africa. Over the last decade this has included a particular interest in young people's engagement in African rural economies. 